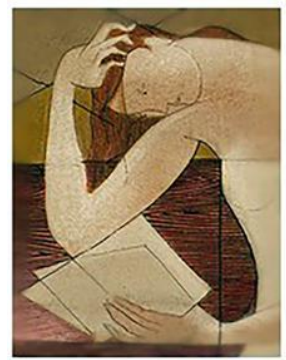

Nau Literária

crítica e teoria da literatura em língua portuguesa PPG-LET UFRGS

ISSN 1981-4526

https://seer.ufrgs.br/NauLiteraria

Vol.16, n. 2 -2020

Dossiê Literatura e Gênero

\title{
Cangoma me chamou': outras fontes para a Rainha Ginga na literatura brasileira
}

\section{Cangoma called me: \\ other sources for the Queen Ginga in the brazilian literature}

Helder Thiago Maia ${ }^{2}$

\begin{abstract}
Resumo: Neste artigo, apresento e analiso cinco textos literários brasileiros que narram a rainha angolana Nzinga Mbandi, mais conhecida no Brasil como Rainha Ginga. Nosso objetivo é pensar como esses textos constroem um imaginário literário sobre a personagem histórica da Rainha Ginga, como estes se relacionam com outros textos históricos e literários e, por fim, como eles podem ser pensados enquanto textualidades coloniais, anticoloniais ou pós-coloniais. Assim, analisamos: o poema Quitubia (1791), de Basílio da Gama, o poema Lá vai verso (1859), de Luís Gama, o texto dramático A revolta da cachaça (1983), de Antonio Callado, o poema $A$ noite não adormece nos olhos das mulheres (1996), de Conceição Evaristo, e o romance Manual Prático do Ódio (2003), de Ferréz.
\end{abstract}

Palavras-chave: Imaginário literário; Literatura brasileira; Rainha Ginga.

Abstract: In this paper, I present and analyze five Brazilian literary texts that narrate the Angolan queen Nzinga Mbandi, better known in Brazil as Rainha Ginga. Our goal is to think about how these texts build a literary imaginary about the historical character of Queen Ginga, how these relate to other historical and literary texts and, finally, how they can be thought of as colonial, anticolonial or postcolonial textualities. Thus, we analyze: the poem Quitubia (1791), by Basilio da Gama, the poem Lá vai verso (1859), by Luís Gama, the dramatic text A revolta da cachaça (1983), by Antonio Callado, the poem A noite não adormece nos olhos das mulheres (1996), by Conceição Evaristo, and the novel Manual Prático do Ódio (2003), by Ferréz.

Keywords: Literary imaginary; Brazilian literature; Queen Ginga.

Anteriormente, no artigo Entra na roda e ginga (2020), analisei a presença da rainha angolana Nzinga Mbandi, mais conhecida no Brasil como Rainha Ginga, na literatura brasileira, através de textos publicados entre 1999 e 2008. Neste primeiro texto, foram discutidas a novela policial $O$ trono da Rainha Jinga (1999), de Alberto Mussa, o conto infanto-juvenil A Ginga da Rainha (2005), de Iris Amâncio, o texto dramático A comida de Nzinga (2005), de Aninha Franco e Marcos Dias, e a história em quadrinhos A Rainha Ginga (2008), de Roberto Benjamin.

\footnotetext{
${ }^{1}$ Cangoma me chamou é uma festa de tambores, é um jongo, é um vissungo, um canto de pessoas negras escravizadas no Brasil, que ganhou vida na voz de Clementina de Jesus, também conhecida como Rainha Ginga (CASTRO, 2017, p. 78). Clementina é a Rainha Ginga cantando "levanta povo, cativeiro já acabou" (JESUS, 1982).

2 Doutor em Literatura Comparada (UFF, 2018), realiza estágio de pós-doutorado, com bolsa da FAPESP, no PPG de Estudos Comparados de Literaturas de Língua Portuguesa da Universidade de São Paulo.
} 


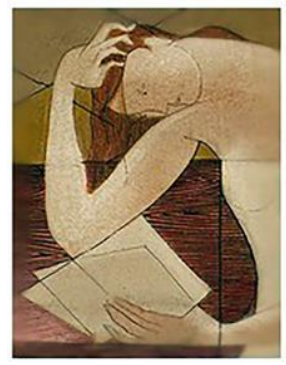

Nau Literária

crítica e teoria da literatura em língua portuguesa PPG-LET UFRGS

ISSN 1981-4526

https://seer.ufrgs.br/NauLiteraria

Vol.16, n. 2 -2020

Dossiê Literatura e Gênero

Neste artigo anterior, pudemos ver como os textos literários convocam textos históricos se não para dialogar diretamente com as narrativas, ao menos para apontar para novas leituras sobre a referida personagem histórica-literária. Mussa (2017), por exemplo, diz que o livro História Geral das Guerras Angolanas (1681), de António Cadornega, serviu para criar "certa verossimilhança etnológica" (MUSSA, 2017, p. 131), enquanto Amâncio (2005) utiliza gravuras de António Cavazzi (1687) e aponta para outros estudos historiográficos e literários (AMÂNCIO, 2005, p. 31), e Franco e Dias (2005) utilizam grande quantidade de dicionários e destacam os trabalhos de Roy Glasgow e Selma Pantoja (FRANCO, DIAS, 2005, p. 34).

Assim, concluímos que o imaginário literário brasileiro sobre a Rainha Ginga estava em diálogo direto tanto com a perspectiva histórica colonial, especialmente de António de Cadornega e António Cavazzi, quanto com perspectivas anticoloniais e pós-coloniais, especialmente de Roy Glasgow e Selma Pantoja. Esse diálogo com o campo da história, obviamente, não é mimético e nem acrítico, e, dessa forma, tanto o diálogo com o texto de Cadornega e Cavazzi permitiriam uma escrita literária anticolonial, quanto o diálogo com Glasgow e Pantoja possibilitariam uma escrita literária colonial.

No entanto, de forma geral, podemos dizer que: a novela de Mussa (2007) narra uma Jinga que tanto é capaz de crueldades, como é também um exemplo de luta que tem reflexos nas ações de resistência à escravidão no Brasil, oscilando, portanto, entre uma perspectiva colonial e pós-colonial sobre a rainha; o conto de Amâncio (2005) constrói Ginga a partir da identificação com meninas negras brasileiras, aproximando-se assim de uma perspectiva angolana anticolonial; enquanto Franco e Dias (2005) e Benjamin (2008) constroem as suas Nzingas e Gingas como sinônimo de luta, resistência e herança cultural, dialogando com tópicos que normalmente são apagados da sua narrativa literária, o que aproxima os textos de uma perspectiva narrativa pós-colonial ${ }^{3}$.

Neste novo artigo, apresento e analiso outros cinco textos literários brasileiros que dialogam com a Rainha Ginga, mas que pouco aparecem na crítica literária que aborda a

\footnotetext{
${ }^{3}$ Sobre as perspectivas coloniais, anticoloniais e anticoloniais e pós-coloniais na narrativa de Nzinga Mbandi consultar Maia e Lugarinho (2020).
} 


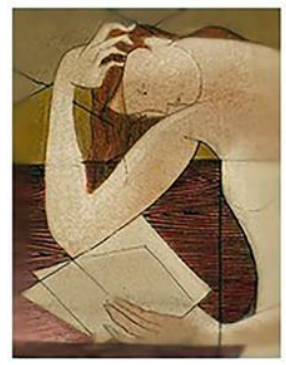

Nau Literária

crítica e teoria da literatura em língua portuguesa PPG-LET UFRGS

ISSN 1981-4526

https://seer.ufrgs.br/NauLiteraria

Vol.16, n. 2 -2020

Dossiê Literatura e Gênero

histórica rainha angolana. São eles: o poema Quitubia (1791), do mineiro Basílio da Gama, o poema Lá vai verso (1859), do baiano Luís Gama, o texto dramático A revolta da cachaça (1983), do fluminense Antonio Callado, o poema A noite não adormece nos olhos das mulheres (1996), da mineira Conceição Evaristo, e o romance Manual Prático do Ódio (2003), do paulistano Ferréz.

Nosso objetivo é pensar como esses textos constroem um imaginário literário sobre a referida personagem, como estes se relacionam com outros textos históricos e literários e, por fim, como eles podem ser pensados como textualidades de perspectiva colonial, anticolonial ou pós-colonial. Para esta tarefa, dividimos as análises em dois blocos: no primeiro deles, analisamos os dois textos dos séculos XVIII e XIX, no segundo, analisamos os três textos dos séculos XX e XXI.

\section{A RAINHA GINGA ENTRE DOIS GAMAS}

Quitubia, de Basílio da Gama (1741-1795), poema escrito em novembro de 1791, é, segundo José Veríssimo (GAMA, 1920, p. 54), depois de O Uraguay (1769), a obra mais importante do autor, ainda que pouco conhecida e estudada. No entanto, assim como a primeira, Quitubia é também uma obra de exaltação de figuras políticas portuguesas. Enquanto O Uraguay (1769) louva o futuro Marquês de Pombal e sua família, Quitubia (1791) louva a Rainha D. Maria I, o que deixa claro a capacidade do autor de se adaptar às circunstâncias políticas de seu tempo, uma vez que é capaz de louvar e receber as benesses desses dois importantes inimigos políticos. Procedimento absolutamente compatível com a relação que o autor também estabelece com os jesuítas e a Companhia de Jesus.

Além de ser um personagem literário, Quitubia é também um personagem histórico que o autor conheceu pessoalmente quando este veio de Angola para Portugal para uma audiência com a rainha portuguesa (BOSI, 2002, p. 295). A sorte de Gama, no entanto, poderia ter sido outra, e o autor talvez pudesse ter conhecido o seu herói negro em ação se o Marquês de Pombal não tivesse perdoado a sua pena de degredo para Angola, cuja causa era 


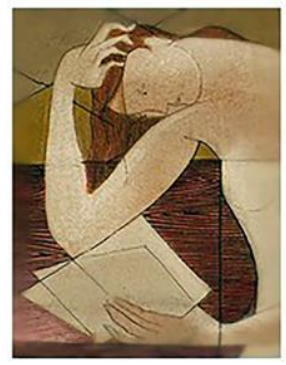

Nau Literária

crítica e teoria da literatura em língua portuguesa

PPG-LET UFRGS

ISSN 1981-4526

https://seer.ufrgs.br/NauLiteraria

Vol.16, n. 2 -2020

Dossiê Literatura e Gênero

suas relações com os jesuítas, por conta de outro poema em que Gama louvava a filha de Pombal ${ }^{4}$.

Ao contrário do seu soneto A Tupac Amaru (GAMA, 1920, p. 219), onde o autor louva aquele que resiste à colonização espanhola, o poema Quitubia louva dois agentes colonizadores portugueses: o capitão-mor Quitubia e a rainha D. Maria I, o que revela que o que não é desejável é o poder colonial espanhol e não a colonização per si. Quitubia é um personagem que, apesar de não duvidar sobre a sua participação no colonialismo português, traz à Rainha não só as suas mãos manchadas de sangue, mas traz também em seu próprio sangue as marcas da complexidade colonial, uma vez que seu pai foi governador do presídio de Ambaca, importante entreposto comercial no sertão angolano, assim como foi também um rico comerciante de pessoas escravizadas, ao mesmo tempo em que sua tia, a "Rainha Ginga", é uma figura de resistência à colonização portuguesa.

Como diz as notas de Gama inclusas no poema, Quitubia, que significa fogo, é o nome de guerra de Domingos Ferreira de Assumpção (GAMA, 1920, p. 149). Este é também o mesmo nome do seu pai, "de cor negra sem demonstração alguma de ter sangue dos brancos, parente da rainha Ginga e muito favorecido dela" (SANTOS, 2014, p. 82-83), e também é o nome de seu avô, que não só lutou por Portugal, como também foi o primeiro padre a celebrar missa no Presídio das Pedras (GAMA, 1920, p. 159). No entanto, segundo o poema, Quitubia teria elevado ainda mais esse nome, levando-o à imortalidade (GAMA, 1920, p. 143). Como diz o poema:

\footnotetext{
Herdaste de teu Pai o nome, e o brio

Que foi terror do pérfido Gentio:

Fez-lhe sentir da nossa espada o pezo;

E levando nas mãos o raio acezo

Queimou a Corte da feroz Rainha.

Mas tu ganhaste, alem dos que elle tinha,

Novo direito á immortalidade:

He teo brazão a tua lealdade (GAMA, 1920, p. 143).
}

\footnotetext{
${ }^{4} \mathrm{O}$ poema que lhe garantiu o perdão de Pombal era uma homenagem à filha e ao casamento da mesma, chamase As nupcias de D. Maria Amalia de Carvalho e Mello, Epitalamio offerecido ao Marquez de Pombal (1769).
} 


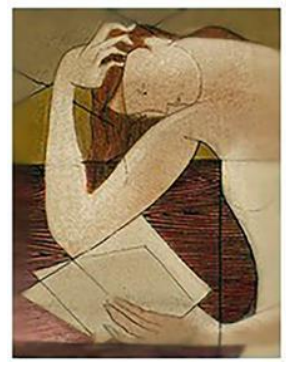

Nau Literária

crítica e teoria da literatura em língua portuguesa

PPG-LET UFRGS

ISSN 1981-4526

https://seer.ufrgs.br/NauLiteraria

Vol.16, n. 2 -2020

Dossiê Literatura e Gênero

Quitubia é um capitão das guerras pretas ${ }^{5}$, à serviço do governo colonial português, que luta não só contra o seu próprio povo, mas também contra a sua própria família, uma vez que a Rainha angolana é sua tia. No entanto, o poema deixa claro também que apesar de lutar e matar por Portugal, o que o tornaria nobre, o seu sangue sendo de "cor escura" será sempre algo que o desmerece (GAMA, 1920, p. 143). Nesse sentido, ainda que a Rainha e a pátria amada sejam sempre Portugal, o lugar e o povo de Quitubia será sempre Angola, e é por isso que ele deve sempre retornar à colônia (GAMA, 1920, p. 147), como podemos ver em:

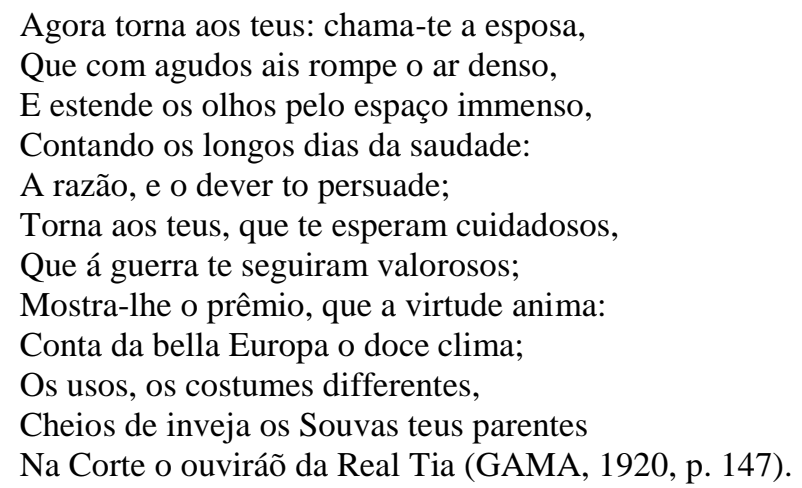

No poema, como explica Alfredo Bosi (2002, p. 295), ao contrário de O Uraguay onde há espaço para a voz dos insurretos, não é possível ouvir a voz dos nativos que resistem à colonização portuguesa. Nesse sentido, não só a Rainha Ginga, mas todo elemento cultural africano, assim como os povos nativos, são narrados sob uma perspectiva colonial, o que significa que são sempre desvalorizados e descritos como bárbaros e selvagens, ao mesmo tempo em que os elementos culturais e o povo português são narrados como superiores, como podemos ver em expressões como "perfido gentio", para se referir aos nativos angolanos, e "Nação leal de gloria cobiçosa", para se referir aos portugueses.

A Rainha Ginga, portanto, é sempre alguém de quem se fala, mas não alguém que assume uma voz no poema. Assim, sabemos que ela teve a sua corte queimada por Quitubia (GAMA, 1920, p. 143), e, nas notas ao poema, sabemos que, após a derrota, Ginga fugiu e

\footnotetext{
${ }^{5}$ As guerras pretas eram guerras provocadas e conduzidas pela coroa portuguesa, cujas tropas eram compostas por africanos, que atacavam reinos e sobas inimigos da corte portuguesa em busca não só da vassalagem dos derrotados, mas principalmente de novas pessoas para escravizar.
} 


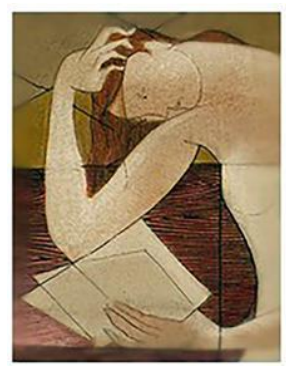

Nau Literária

crítica e teoria da literatura em língua portuguesa PPG-LET UFRGS

ISSN 1981-4526

https://seer.ufrgs.br/NauLiteraria

Vol.16, n. 2 -2020

Dossiê Literatura e Gênero

depois, em 1744, teria capitulado e pedido paz a Portugal (GAMA, 1920, p. 149). Resumidamente, a Rainha Ginga é uma "feroz rainha" (GAMA, 1920, p. 143) derrotada por um "forte" e "esforçado" Quitubia, que submete não só a ela, mas (exageradamente), conforme o texto (GAMA, 1920, p. 146), toda a África ao poder português.

Por fim, é preciso dizer que o texto de Basílio da Gama não dialoga explicitamente com nenhum outro relato histórico que não seja a própria história possivelmente narrada por Quitubia na audiência com a Rainha portuguesa D. Maria I, uma vez que o poema não extrapola a própria narrativa de Quitubia seja sobre Ginga, seja sobre a história angolana. Além disso, é preciso dizer também que a Rainha Ginga narrada no poema não se refere à famosa rainha e heroína nacional angolana Nzinga Mbandi/D. Ana de Sousa, uma vez que esta viveu e morreu entre 1582 e 1663 , enquanto o poema se refere a fatos que ocorreram no século XVIII, ao redor de 1744.

A partir das "Notas do poeta", sabemos que a avó da Rainha Ginga ao qual o poema se refere é D. Verônica. Com essa informação e em diálogo com a cronologia dos governantes do Ndongo e Matamba estabelecida pelo historiador Fernando Campos (2007), podemos dizer que a Rainha Ginga narrada por Basílio da Gama é na verdade D. Ana II/Ana Guterres da Silva, que não só governou entre 1742 e 1756 e era neta de D. Verônica I, que governou entre 1681 e 1721, como também sofreu efetivamente uma grande invasão portuguesa em Matamba e assinou tratado de vassalagem com Portugal (CAMPOS, 2007).

Assim sendo, apesar de o texto promover uma confusão entre as duas rainhas angolanas, podemos afirmar, partindo das notas do poema, que não se trata aqui da Rainha Nzinga Mbandi. No entanto, a partir de estudo anterior (MAIA, LUGARINHO, 2020a), podemos dizer que o imaginário literário sobre Nzinga, inclusive na própria literatura angolana, como podemos ver em Joaquim Cordeiro da Matta (1882), é também construído por textos que narram outras Rainhas Gingas sem estabelecer diferenças entre elas.

Cinquenta e nove anos depois do poema de Basílio da Gama, em 1850, era promulgada no Brasil a Lei Eusébio de Queirós, que proibia a entrada no Brasil de africanos escravizados. No entanto, somente quatro anos depois, com a Lei Nabuco de Araújo, é que o 


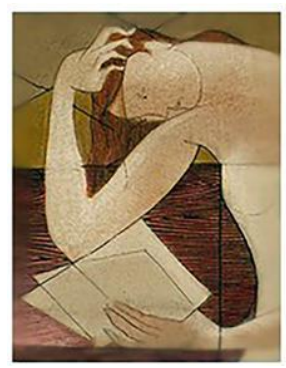

Nau Literária

crítica e teoria da literatura em língua portuguesa PPG-LET UFRGS

ISSN 1981-4526

https://seer.ufrgs.br/NauLiteraria

Vol.16, n. 2 -2020

Dossiê Literatura e Gênero

tráfico de pessoas negras, sequestradas em África e escravizadas no Brasil, começou a ser realmente reprimido em território brasileiro. $\mathrm{Na}$ literatura brasileira, predominava neste período a mística indianista, que ao mesmo tempo em que alimentava a ideia de uma literatura genuinamente brasileira a partir de elementos humanos e culturais indígena e português, excluía desse espaço qualquer traço humano ou cultural africano. $O$ guarani, de José de Alencar, talvez a mais significativa obra desse momento, foi lançada em 1857.

Nesse contexto, em 1859, reescrevendo a história de negros e negras brasileiras, e furando a hegemonia literária branca, ao mesmo tempo em que a romancista Maria Firmina dos Reis ${ }^{6}$ publica Úrsula, primeiro romance abolicionista, o poeta Luís Gama ${ }^{7}$ publica Primeiras trovas burlescas de Getulino, possivelmente o primeiro livro de poesia onde o autor se anuncia e deseja ser visto como negro, conforme Ligia Fonseca Ferreira (2019, p.109), ainda que não se trate necessariamente de poesia abolicionista (FERREIRA, 2019, p. 116). Dois anos depois, em 1861, o livro de Gama ganha uma segunda edição corrigida e aumentada.

Na edição de 1859, o livro de Gama é composto de vinte poemas do autor, além de três poemas do seu amigo José Bonifácio, o moço, enquanto isso, na edição de 1861, o livro é publicado com trinta e nove poemas de Gama, além de dez poemas de José Bonifácio, o que revela um aumento significativo entre a primeira e a segunda publicação. De forma geral, podemos dizer que os dois livros são compostos principalmente de poemas satíricos. Nesse sentido, é importante apontar também que a maior parte dos poemas de Gama, inclusive a própria contracapa do livro, é acompanhada de epígrafes de poetas satíricos portugueses, especialmente Faustino Xavier de Novaes $(1820-1869)^{8}$. No entanto, como argumenta Ferreira:

Luiz Gama se distingue por seu ecletismo, graças à variedade de gêneros (sátira política e de costumes, paródias heróico-cômicas, bestialógico ou non-sens, poemas líricos), de estilos (influências clássicas e romantismo), de temas (o mundo às avessas, a corrupção dos políticos, a hipocrisia racial da sociedade imperial, o preconceito racial, o anticlericalismo, a frivolidade

\footnotetext{
${ }^{6}$ Sobre a vida e a obra de Maria Firmina dos Reis consultar Fernanda Miranda (2019).

${ }^{7}$ Sobre a vida e a obra de Luís Gama consultar Ligia Fonseca Ferreira (2011).

${ }^{8}$ Sobre a relação entre a poesia de Gama e de Xavier de Novaes, consultar Ferreira (2019).
} 


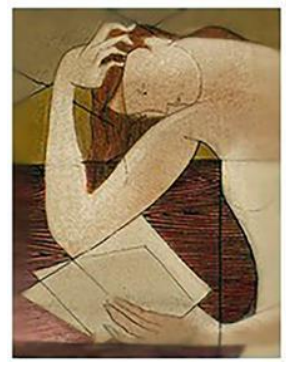

Nau Literária

crítica e teoria da literatura em língua portuguesa

PPG-LET UFRGS

ISSN 1981-4526

https://seer.ufrgs.br/NauLiteraria

Vol.16, n. 2 -2020

Dossiê Literatura e Gênero

feminina, a caricatura de tipos sociais, a inépcia dos magistrados, o amor, o escravo), de linguagens e referências culturais (erudito X popular ou coloquial, africanismos) (FERREIRA, 2019, p.128).

Lá vai verso!, quarto poema da edição de 1859 e segundo poema da edição de 1861, que também conta com epígrafe de Xavier de Novaes, é um poema onde o sujeito lírico define: que tipo de poeta ele quer ser - aquele que escreve em linhas tortas, com pluma leve, mas como um vulcão ardente; como as ninfas participam do seu jogo poético - que o observem arder, mas que também apregoem o seu nome no firmamento; que musa o inspira A musa de Guiné, cor de azeviche, capaz de render leões, que toca um berimbau; o que deseja - superar antigos poetas em gloria; como quer ser visto - como um Orfeu de carapinha, que despreza a lira, mas decanta a marimba; sobre o que ou sobre quem falará - gente luminosa e trapaceira, que reza a cartilha da esperteza, como deputados, ministros, senadores e diplomatas, incluindo a si mesmo; e, por fim, entre quem sua poesia será recebida como festa - entre os netos da Ginga, seus parentes.

Assim sendo, com o poema Lá vai verso!, Luís Gama realiza um procedimento inédito, não só na literatura brasileira mas também na literatura angolana e portuguesa, ao publicar aquela que é possivelmente a primeira representação anticolonial sobre a Rainha Ginga, antecipando-se inclusive ao poeta angolano Joaquim Cordeiro da Matta, que em 1882, com o ensaio A verdadeira rainha Ginga, realiza o mesmo procedimento na literatura angolana. Essa mudança de perspectiva inaugurada por Gama reescreve a história colonial, e a Ngola do Ngondo e Matamba deixa de ser narrada como uma figura bárbara e selvagem, como vimos em Basílio da Gama (1791), para se tornar uma figura heroica, um símbolo e orgulho da resistência ao colonialismo português, como podemos ver em:

Nem eu próprio á festança escaparei;

Com foros de Africano fidalgote,

Montado n'hum Barão, com ar de zóte-

Ao rufo do tambor, e dos zabumbas,

Ao som de mil aplausos retumbantes,

Entre os netos da Ginga, meus parentes,

Pulando de prazer e de contentes-

Nas danças entrarei d'altas cayumbas (GAMA, 1859, p.19). 


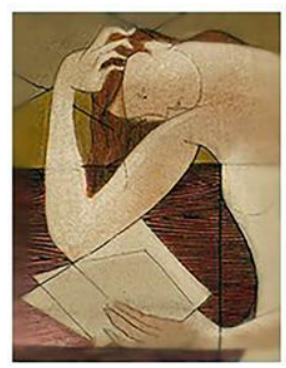

Nau Literária

crítica e teoria da literatura em língua portuguesa PPG-LET UFRGS

ISSN 1981-4526

https://seer.ufrgs.br/NauLiteraria

Vol.16, n. 2 -2020

Dossiê Literatura e Gênero

Como dissemos anteriormente, além de Xavier de Novaes, Gama dialoga explicitamente em suas epígrafes com outros poetas satíricos, como o português Nicolau Tolentino (1740-1811) e o brasileiro Gregório de Matos (1636-1696). Por conta disso, é muito provável que também não ignorasse a obra do mais conhecido poeta satírico português, Manuel Maria du Bocage (1765-1805). Em verdade, o poema de Gama nos parece uma resposta a quatro sonetos, atribuídos a Bocage $^{9}$, que abordam a Rainha Ginga, são eles: $O$ quinto neto da Rainha Ginga, de 1781, Preside o neto da Rainha Ginga, de 1790, Soneto ao Árcade Lereno, mais conhecido como A nojenta prole da Rainha Ginga, de 1790, e Metamorfose, de 1792.

Lidos em conjunto, podemos inferir duas características comuns aos quatro sonetos: o ataque a terceiros através de um ataque à Rainha Ginga e sua possível descendência, o primeiro soneto ataca o político português Marquês de Pombal, enquanto os outros atacam o presidente da Nova Arcádia, o poeta e padre brasileiro negro Domingos Caldas Barbosa; além da utilização de tópicos raciais para desumanizar as vítimas desses ataques. Os quatro sonetos, ao atacarem seus alvos, atribuem os supostos defeitos destes a uma descendência da Rainha Ginga, o que deixa claro como era racista o imaginário colonial literário português sobre a rainha naquele momento.

Em $O$ quinto neto da Rainha Ginga, o poeta recria a ideia de que o Marquês era um homem mestiço, ao atribuir ao seu avô de cinco gerações anteriores o envolvimento com uma mulher negra chamada de Mãe Marta, o que teria feito nascer uma sucessão "preta". O sujeito lírico, portanto, sugere que o Marquês volte ao solar da Mata Escura, local de onde provinha a sua família, e termina por atribuir os erros da política pombalina ao fato dele ser "um quinto neto da rainha Ginga", sugerindo assim uma relação de parentesco entre Marta, Ginga e Pombal.

Em Preside o neto da Rainha Ginga temos um ataque amplo não só a Caldas Barbosa, mas também à Nova Arcádia de Lisboa, o que inclui, portanto, uma descrição satírica dos poetas que participam da reunião, que aplaudem as "frivolidades" do presidente, mas também

\footnotetext{
${ }^{9}$ Sobre os poemas de Bocage, consultar Maia e Lugarinho (2020b).
} 


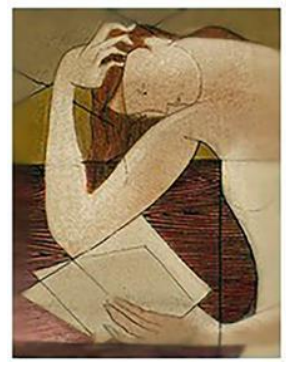

Nau Literária

crítica e teoria da literatura em língua portuguesa PPG-LET UFRGS

ISSN 1981-4526

https://seer.ufrgs.br/NauLiteraria

Vol.16, n. 2 -2020

Dossiê Literatura e Gênero

da plateia que os assistem, chamados de "corja vil, aduladora e insana". No entanto, os ataques se voltam principalmente contra Caldas Barbosa, presidente da Arcádia, que não só é chamado de orangotango, como também tem sua gestualidade associada à prática de feitiçaria, entendida no poema como algo selvagem. Como aponta Fernando Morato (2018, p. 95), Caldas Barbosa é o único a receber críticas que recaem exclusivamente sobre o seu corpo, seja o corpo performado, seja o corpo herdado.

Os ataques ao corpo herdado, à descendência, do poeta se intensificam no Soneto ao Árcade Lereno, que já em seu primeiro verso afirma que é nojenta a "prole" da rainha Ginga. O poeta diz ainda que Caldas é um "sabujo labrador", um "estúpido", "um néscio", "um parvo", e intensifica seu processo de desumanização ao novamente se referir ao brasileiro, mais uma vez, o aproximando a espécies de macaco, como mico e saguim. Além disso, há ataques à sua poesia, que supostamente exalaria fedor, como se o corpo contaminasse o verso, e afirmações de que Caldas quer se "meter no cú das pessoas", o que nos parece uma referência a aspectos moralistas da poesia de Caldas Barbosa.

Por fim, no soneto Metamorfose, a dedicatória já promove ataques racistas ao corpo de Caldas Barbosa ao enunciar "Ao trovista Caldas, pardo de feições e grenha crespa e revolta". Neste, Bocage não só sugere que o poeta é um macaco sem rabo vindo do Brasil, de descendência Ginga, mas também diz que o mesmo em Portugal se diz versista, quando a sua verdadeira ciência seria a mandinga e o seu Apolo, o diabo. Assim sendo, podemos afirmar que nos quatro sonetos são constantes os ataques à origem de Caldas Barbosa, como também são constantes os ataques ao seu corpo e à sua descendência negra.

A Rainha Ginga, portanto, é nos sonetos tomada como um imaginário já sedimentado de inumanidade, selvageria e barbárie, por isso a afirmação da sua descendência parece, ao menos entre os poemas aqui enunciados, o suficiente para desumanizar inimigos. Este procedimento, no entanto, não ficou restrito aos ataques portugueses a Caldas Barbosa, uma vez que no Brasil, conforme Hebe Maria Mattos (1999:39), Antônio Rebouças (1798-1880), intelectual, deputado e advogado negro baiano, pai de André Rebouças, intelectual, 


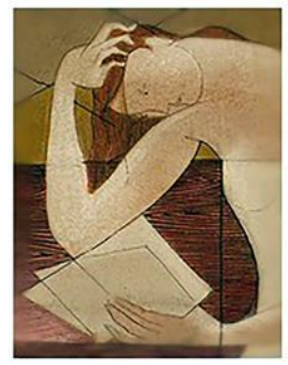

Nau Literária

crítica e teoria da literatura em língua portuguesa PPG-LET UFRGS

ISSN 1981-4526

https://seer.ufrgs.br/NauLiteraria

Vol.16, n. 2 -2020

Dossiê Literatura e Gênero

engenheiro, abolicionista e amigo de Luís Gama, também foi chamado por inimigos políticos em Sergipe de "miserável neto da rainha Jinga".

Assim, é importante apontar que a descendência e o corpo negro herdados da Rainha Ginga são invocados por Gama, em Lá vai verso!, como motivos de orgulho. O poema, portanto, configura-se não só como uma resposta ao racismo de Bocage, mas também como uma resposta dada por Luís Gama, o Orfeu de Carapinha, em nome de Caldas Barbosa, de Antônio Rebouças e de todos os outros netos da Rainha Ginga.

É importante dizer, no entanto, que esse procedimento de reabilitação e de reescritura de uma figura histórica, que transforma uma imagem negativa de perspectiva narrativa colonial em uma imagem positiva de perspectiva anticolonial, aparece no livro de Gama também através da figura de Calabar. Como aponta Ferreira (2019, p. 117), no poema Calabar, um dos poemas de Bonifácio que fazem parte do livro, a figura do "traidor" da pátria portuguesa, e consequentemente da história colonial brasileira, é transformada, assim como Ginga, em uma personagem-símbolo da luta contra a opressão colonial, como podemos ver em:

\footnotetext{
A quem trahiste, heroe? - na vil poeira

Que juramento te prendia a fé?!

Escravo por escravo - essa bandeira

Foi de hum soldado-lá ficou de pé!

Viu o sol entre as brumas do futuro

-Elle que por si só nada podia;

Quiz vingar-se também,- - no sonho escuro.

Quiz ter também seu dia! (GAMA, 1859, p. 124).
}

Por fim, é preciso dizer que a palavra "ginga" também é utilizada por Gama como o verbo "gingar", como podemos ver no poema Caricatura que diz "Lá ginga na praça/ Gentil namorado;/ Vai tam adamado" (GAMA, 1859, p.21). Curiosamente, no entanto, neste poema, a ginga, o rebolado, ou como diz o poema os "Tregeitos femineos,/ Pisar delicado,/ Andar compaçado" (GAMA, 1859, p.22), do gentil namorado, é entendido como algo depreciativo, como perda de masculinidade, o que o transforma em um "nescio namorado", "desfructavel", "que ao ridiculo se presta" (GAMA, 1859, p.22). 


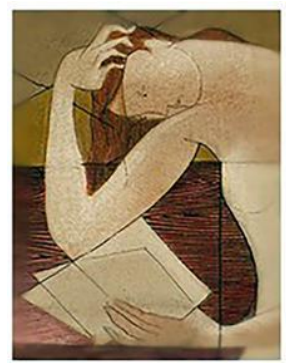

Nau Literária

crítica e teoria da literatura em língua portuguesa PPG-LET UFRGS

ISSN 1981-4526

https://seer.ufrgs.br/NauLiteraria

Vol.16, n. 2 -2020

Dossiê Literatura e Gênero

\section{A COISA tá PRETA ${ }^{10}$ : ANTONIO CALlAdO, CONCEIÇÃO EVARISTO, FERRÉZ E A RAINHA GINGA}

Escrita em 1959, A revolta da cachaça é um texto dramático que só foi publicado em 1983, juntamente com outras três peças do mesmo autor ${ }^{11}$, que compõem o que é denominado como "Teatro negro" de Antonio Callado. O texto da peça, conforme Ligia Chiappini (2004, p. 107), foi dedicado e provavelmente escrito para ter o ator Grande Otelo como protagonista, no entanto, ficou inédito até 1995, quando foi encenado com o ator Tony Tornado no papel de Ambrósio, Tessy Callado, filha do autor, no papel de Dadinha, e Walney Costa no papel do dramaturgo Vito, com direção de Moacir Chaves ${ }^{12}$.

Em um único ato, que se passa na "grande sala de estar da casa de Vito, em Petrópolis. Ambiente bem serrano e próspero" (CALLADO, 2004, p. 7), podemos dizer que o tema principal da peça é o racismo, que é discutido e encenado a partir, principalmente, de três pontos: o lugar do ator negro no teatro brasileiro, as relações interraciais e a violência policial. Nesse sentido, é importante dizer também que o texto de A revolta da cachaça é uma resposta direta não só à montagem de Pedro Mico, peça anterior de Callado, mas também a outras peças teatrais ${ }^{13}$, que utilizavam atores brancos pintados de preto no lugar de atores negros.

Além disso, podemos dizer também que a peça é um metateatro, na medida em que, como argumentam Patrícia Nagakome e Regina Sousa (2011, p. 69), "a peça fala do processo de criação de uma peça", cujo título também se chamaria A revolta da cachaça. No entanto, enquanto o texto discute a escrita e a encenação de uma revolta nativista ${ }^{14}$, a peça

\footnotetext{
${ }^{10}$ A coisa tá preta é uma música do rapper e poeta paulistano Rincon Sapiência, que faz parte do álbum Galanga Livre (2017), onde se canta Nzinga a partir de uma perspectiva anticolonial, como podemos ver nos versos: "Ritmo tribal no baile nóis ginga/ Cada ancestral no tronco nóis vinga/ Cada preto se sente Zumbi/ E cada preta se sente a Nzinga" (SAPIÊNCIA, 2017).

${ }^{11}$ As outras três peças são Pedro Mico (1957), O tesouro de Chica da Silva (1958) e Uma rede para Iemanjá (s.d.).

${ }^{12}$ Sobre a montagem ver <https://www1.folha.uol.com.br/fsp/1995/6/07/ilustrada/18.html>. Acesso em 30 de mar 2020.

13 Como explica Chiappini (2004, p. 121), enquanto as representações do Teatro Experimental do Negro, fundado por Abdias Nascimento, utilizavam somente atores negros, o teatro mais comercial daquele momento recorria constantemente ao blackface.

${ }^{14}$ A Revolta da Cachaça foi uma rebelião ocorrida no Rio de Janeiro, entre 1660 e 1661, onde fabricantes de cachaça se rebelaram contra o governo de Salvador Correa de Sá, que havia liberado a produção de cachaça sob
} 


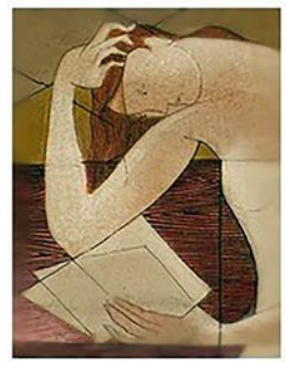

Nau Literária

crítica e teoria da literatura em língua portuguesa PPG-LET UFRGS

ISSN 1981-4526

https://seer.ufrgs.br/NauLiteraria

Vol.16, n. 2 -2020

Dossiê Literatura e Gênero

efetivamente encenada trata da revolta de Ambrósio, seja porque Vito não conclui a escrita do texto dramático, seja pelo lugar marginal a que está enclausurado por ser um ator negro retinto. Como podemos ver nos dois trechos abaixo, a peça nunca terminada seria a grande oportunidade da carreira de Ambrósio.

\begin{abstract}
As outras peças você acabou todas. Não falhou nenhuma. Foram tantas, de tanto sucesso, que diziam até que tua máquina de escrever tinha virado máquina registradora. Mas era tudo peça pra ator brasileiro normal, quer dizer, representante dessa negrada disfarçada que está aí (faz um gesto largo, abrangente), gente fosca, cafuza, mulato-clara ou nem tão clara assim, gente chocolate-de-leite, gente marrom puxando pra bege, jabuticaba pra roxinho leve, gente luto aliviado, quer dizer, carapinha e beiçola mas o couro já desbotando, e o olho verde - assim tudo bem! Mas peça de preto honesto, preto-preto, preto sem habilidade e hipocrisia, da carapinha à córnea amarela e à unha roxa, essa não tem, essa você não acabou nunca! (CALLADO, 2004, p. 56-57).
\end{abstract}

Estou de saco cheio de fazer papel marginal, o cara que fica na praia espiando barco, no meiofio olhando automóvel, sempre na beira, na margem. Vim aqui cobrar a fama que você me deve. Vim pra morar, pra morrer. Mas no meio do rio ou da rua. Chega de margem (CALLADO, 2004, p.93).

A peça encenada, portanto, narra a ida de Ambrósio à casa de Vito e Dadinha, em Teresópolis, com o objetivo de fazer o dramaturgo terminar a peça A revolta da cachaça. Antes de chegar à casa, Ambrósio, um ator negro condenado a fazer papéis coadjuvantes, envia anonimamente um barril de cachaça, que serviria às comemorações dos dez anos da peça inacabada. Vito, como explica Chiappini (2004, p. 108), é um intelectual branco que trata o negro de forma paternalista, enquanto Dadinha é uma atriz branca que vê o negro como um objeto sexual.

Ambrósio está ali para cobrar a peça que lhe traria fama, que o levaria ao centro do palco e o retiraria das margens, e Vito, amigo pessoal, é um dramaturgo de sucesso, cuja única peça inacabada é aquela que teria um negro retinto como protagonista. Ambrósio já está envelhecido e adoentado, por isso não quer algo que discuta necessariamente a negritude (CALLADO, 2004, p. 64) ou que reflita sobre a arte dramática (CALLADO, 2004, p.62), quer apenas uma peça como tantas outras escritas por Vito, que o leve para o centro do palco, e lhe restitua a gloria negada durante toda uma vida.

a condição da cobrança de altos impostos. A revolta foi comandada pelos irmãos brancos e proprietários de alambiques Agostinho e Jerônimo Barbalho, com o apoio do negro liberto João Angola. 


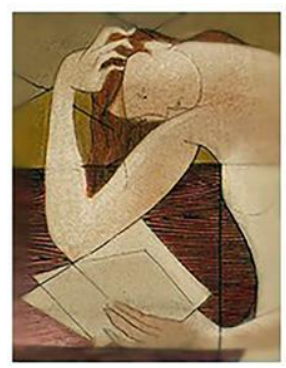

Nau Literária

crítica e teoria da literatura em língua portuguesa PPG-LET UFRGS

ISSN 1981-4526

https://seer.ufrgs.br/NauLiteraria

Vol.16, n. 2 -2020

Dossiê Literatura e Gênero

Vito, como tantas outras vezes, diz que terminará a peça, mas só fará isso depois de finalizar a que estava escrevendo. Ambrósio recusa essa solução, quer a peça pronta e só irá embora com ela. Diante do impasse, Ambrósio ameaça Vito com uma arma, e eles entram em luta corporal. Vito tem um leve machucado, curável com um band-aid, enquanto Ambrósio foge e termina morto nos jardins da casa. A polícia sugere ao casal que foi um ataque do coração, uma vez que supostamente, segundo a versão policial, o tiro dado teria atingido apenas o joelho. Dadinha confirma a versão da polícia, e Ambrósio, ao invés de ser levado para um hospital, é levado diretamente para um necrotério.

Na peça encenada, o ator negro segue, ainda quando protagonista de uma peça, como Ambrósio, condenado ao papel de "bandido", ao mesmo tempo em que a peça inacabada parece sugerir que ainda não há espaço para o ator negro, nem como protagonista, nem como herói da história brasileira. Talvez, como ironicamente sugere Dadinha (CALLADO, 2004, p. 50), o único lugar possível para o negro protagonista no teatro brasileiro ainda seja, naquele momento, a encenação de $O$ demônio familiar $^{15}$ (1857), de José de Alencar, ou $A$ viúva alegre $^{16}$ (1905), de Franz Lehar.

Segundo a peça encenada, o texto de $A$ revolta da cachaça teria três versões não finalizadas por Vito. A Rainha Ginga aparece na primeira versão, quando na chegada de pessoas negras escravizadas no cais Pharoux, atual Praça XV no Rio de Janeiro, o negreiro abria o seu ventre e enquanto os homens e mulheres escravizadas caminhavam para o mercado de escravos, os deuses e deusas africanos, comandados pela Rainha Ginga, se dirigiam ao Morro do Castelo, local conhecido pela grande quantidade de pessoas negras, onde morava João Angola, herói negro que seria interpretado por Ambrósio. Vejamos, então, esse trecho da peça, através de Ambrósio, que rememora o texto escrito e não finalizado:

- E o marinheiro doido, o capitão, o negreiro lelé da cuca? Abria o ventre do navio pra negrada sair, ali no cais Pharoux, e berrava: "Homem e mulher pro mercado de escravos da rua Direita... Deuses e deusas por morro do Castelo." Aí era o desfile, o primeiro desfile, os da rua Direita estropiados, acorrentados, sangrando...Pro Castelo, comandados pela rainha Ginga, iam

\footnotetext{
${ }^{15}$ Sobre o lugar do negro na peça de Alencar, consultar Abdias do Nascimento (2004).

${ }^{16}$ Sobre a relação entre Franz Lehar e o nazismo, ver por exemplo <https://www.dw.com/pt-br/1905-estreia-dea-vi\%C3\%BAva-alegre-em-viena/a-371910>. Acesso 01 mai 2020.
} 


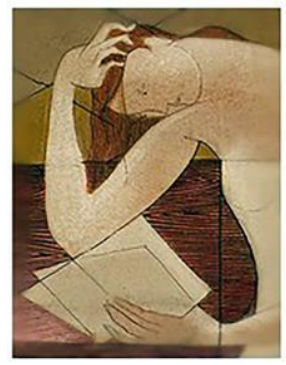

Nau Literária

crítica e teoria da literatura em língua portuguesa PPG-LET UFRGS

ISSN 1981-4526

https://seer.ufrgs.br/NauLiteraria

Vol.16, n. 2 -2020

Dossiê Literatura e Gênero

Xangô, Omulu, Ogum com suas ferramentas, Iansã, Oxum. E toda linda, lustros de tão negra, vestida de lírio, Iemanjá (CALLADO, 2044, p. 34-35).

Essa cena, entre as muitas coisas que pode indicar, nos chama atenção tanto por apontar para o Morro do Castelo como um espaço de resistência, de onde surgiriam heróis da libertação negra, como foi João Angola durante a revolta da cachaça, quanto por mostrar, como aponta Inocência Mata (2014, p. 25-26), que a Rainha Ginga é um símbolo não só da resistência angolana ao domínio português, mas também um símbolo da resistência negra brasileira, e parte da memória cultural do mundo afro. Ginga, portanto, é aquela que guia os deuses ao lugar onde não só serão adorados, mas também ao lugar de onde a resistência poderá ser organizada.

A peça, portanto, produz uma perspectiva anticolonial sobre a Rainha Ginga, seja pela resistência que ela ajuda a organizar, seja pela valorização do elemento cultural negro africano. No entanto, apesar de narrar um fato histórico real, a Revolta da Cachaça, e consequentemente encenar a vida de personagens reais, como Jerônimo e Agostinho Barbalho, não há indicações, assim como também não conseguimos inferir, sobre quais seriam os textos históricos com os quais a peça dialoga, seja para abordar a Rainha Ginga, seja para abordar a rebelião e os outros personagens.

Trinta e sete anos depois, em 1996, aparece o primeiro texto, localizado por mim, de autoria feminina a abordar a Rainha Ginga ${ }^{17}$, o poema $A$ noite não adormece nos olhos das mulheres, da mineira Conceição Evaristo, publicado pela primeira vez em Cadernos Negros, volume $19^{18}$, junto a outres vinte e três poetas selecionados por João Silvério Trevisan, Oswaldo de Camargo e Benedita Aparecida Lopes (ANTÔNIO, 2005, p. 106).

O poema, que está dedicado à memória de Beatriz Nascimento, importante historiadora, professora e ativista pelos direitos de negros e mulheres, que havia sido assassinada em janeiro de 1995, aborda a relação entre memória, ancestralidade, resistência e

\footnotetext{
${ }^{17}$ Os três textos escritos por mulheres, localizados por mim, são o poema A noite não adormece nos olhos das mulheres (1996), de Conceição Evaristo, o conto infanto-juvenil A Ginga da Rainha (2005), de Iris Amâncio, e A comida de Nzinga, de Aninha Franco e Marcos Dias.

${ }^{18} \mathrm{O}$ poema foi publicado também em O livro da saúde das mulheres negras: nossos passos vêm de longe (2000), de Jurema Werneck, Maisa Mendonça e Evelyn White; em Poemas da recordação e outros movimentos (2008), de Conceição Evaristo, e em Cadernos negros: os melhores poemas (2008).
} 


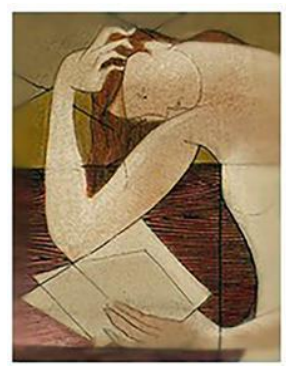

Nau Literária

crítica e teoria da literatura em língua portuguesa PPG-LET UFRGS

ISSN 1981-4526

https://seer.ufrgs.br/NauLiteraria

Vol.16, n. 2 -2020

Dossiê Literatura e Gênero

o corpo-vivência de mulheres negras. Nesse sentido, o poema parece sugerir que a noite não apagará a memória das mulheres, que o sono e a noite não fecharão os olhos das mulheres, que o corpo das mulheres retém e produz a vida capaz de afastar os cálices de lágrimas e que a noite jamais existirá nos olhos das mulheres, pois em cada gota de sangue derramado há um fio invisível e tônico que pacientemente costura uma resistência feminina milenar.

Nessa relação entre noite e mulheres, a noite não se apresenta às mulheres como um espaço do descanso, do medo ou da invisibilidade, ao contrário, a noite habitada por essas mulheres negras é espaço de memória e de resistência, mas também de "molhadas lembranças" e de vida. E nesse sentido é o corpo "lua fêmea", como um corpo-vagalume, que resiste à invisibilidade que a noite poderia produzir, e para isso se vale não só dos seus olhos, mas também de suas lágrimas, de suas "vaginas abertas" e dos seus "líquidos lembradiços".

Nesse contexto, Nzinga Mbandi aparece, na terceira estrofe do poema, junto a outras mulheres e meninas-luas, como aquelas que são capazes não só de reter e expulsar a vida através de seus corpos, mas como aquelas que são capazes de afastar os cálices de lágrimas da vida das mulheres. Além disso, as mulheres negras nomeadas no poema - Ainás, Nzingas, Ngambeles - são capazes também de costurar a milenar e ancestral resistência das mulheres negras.

Assim, Nzinga aparece em A noite não adormece nos olhos das mulheres como parte da memória afro-brasileira, a partir de uma perspectiva pós-colonial, que se constrói não só através de sua figura, que articula lágrima e luta, vida e resistência, mas também pela relação que o poema estabelece entre a noite e o corpo feminino. No entanto, não há um diálogo explícito com textos históricos sobre Nzinga, uma vez que sua figura parece recuperada de uma oralidade milenarmente tecida entre mulheres negras.

Por fim, em 2003, Ferréz, paulistano, escritor, poeta e rapper, publica o seu terceiro livro-lâmina, o romance Manual Prático do Ódio, o qual também ajuda a construir a figura de Nzinga Mbandi na literatura brasileira. Neste romance, um narrador onisciente, ajudado por diálogos transcritos de forma indireta, relata a trajetória de um grupo de criminosos da periferia de São Paulo, formado por Régis, Celso Capeta, Aninha, Neguinho da Mancha na 


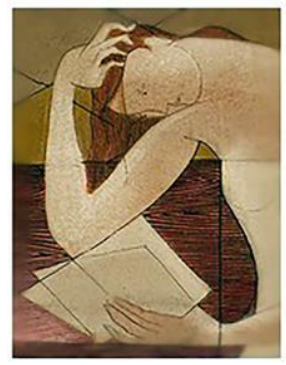

Nau Literária

crítica e teoria da literatura em língua portuguesa PPG-LET UFRGS

ISSN 1981-4526

https://seer.ufrgs.br/NauLiteraria

Vol.16, n. 2 -2020

Dossiê Literatura e Gênero

Mão, Mágico e Lucio Fé, que planejam um ambicioso assalto a banco. Como explica Vinicius Carneiro,

Seu objetivo é realizar um assalto na tentativa de escalar uma etapa na carreira do crime organizado. Estes e outros criminosos, assim como moradores da favela e sujeitos que, por um motivo ou outro, passam pela periferia, são apresentados em segmentos sucessivos do romance. Compõem-se, dessa maneira, instantâneos de quem transita na periferia: personagens que vêm de fora para passar por ali; que partem dela para depois voltarem; ou que estão restritas a seus limites. $\mathrm{O}$ entrelaçamento das histórias finda por evidenciar uma cartografia rizomática da região (CARNEIRO, 2017, p. 254).

Ao longo da narrativa, como aponta Eliane Silveira (2005, p. 34), intercalados aos episódios vividos pelos criminosos e por seus rivais, são apresentadas histórias de outras personagens que habitam a mesma periferia, cuja presença na narrativa não só contribui para a construção do espaço onde ocorre a trama, a favela, como também, de alguma forma, explica a existência da violência, do crime e do ódio na região. A partir da afirmação de que o crime não é o único destino para as pessoas que habitam as periferias de São Paulo, ainda que a violência e o ódio atinja a todos que habitam estes espaços, somos apresentados a outros personagens, entre os quais se inclui Paulo, cuja história nos levará a Nzinga Mbandi.

Paulo, neto de Dona Lavinha, é primeiro apresentado como um grande leitor de clássicos literários, aquele que encontra abrigo nos livros, assim como seu falecido pai, que lê de madrugada, para evitar misturar a leitura à música alta dos seus vizinhos, e que de manhã vai para o trabalho em uma metalúrgica. Além disso, Paulo também é descrito como um crítico do comportamento da sua comunidade, afinal, repudiava e odiava, por exemplo, a fofoca do bairro, uma vez que convivia desde pequeno com as fofocas sobre seu pai, assim como também odiava ver os moradores jogando lixo nos córregos, que acabavam por transbordar e invadir as casas, e odiava ver o alcoolismo destruindo as relações familiares, como resume o narrador:

Ele odiava tudo isso, odiava viver naquele lugar, no mesmo lugar que puxou seu pai para a cova e fez sua mãe fugir com o patrão e o abandonar ainda criança, mas sabia que o lugar tinha um ritmo, e ele outro, sabia que não devia entrar no ritmo do lugar, e sim seguir o seu próprio (FERRÉZ, 2014, p. 792). 


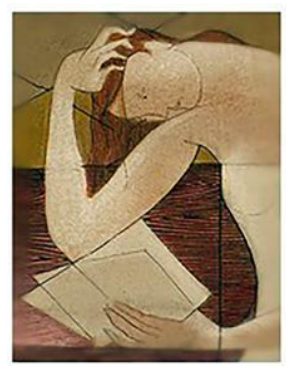

Nau Literária

crítica e teoria da literatura em língua portuguesa PPG-LET UFRGS

ISSN 1981-4526

https://seer.ufrgs.br/NauLiteraria

Vol.16, n. 2 -2020

Dossiê Literatura e Gênero

No entanto, Paulo também vive o amor na comunidade, seja em sua relação com a avó Dona Lavinha, seja em sua relação com a namorada Auxiliadora, a doméstica pernambucana que "enfrentou de tudo na cidade grande" e que amava Paulo pelo fato dele viver na contramão do bairro. Além disso, Paulo, um homem negro, "respeitava os orixás", conhecia o seu passado e a história do seu povo, e sonhava ensinar aos seus filhos uma outra história sobre opressores e oprimidos, como podemos ver nesse trecho:

Paulo era negro, sabia tudo sobre a história de seus ancestrais, conhecia de cor as histórias fantásticas de Zumbi, de Anastácia e era apaixonado pela rainha Nzinga, sempre se imaginava contando a história dos verdadeiros heróis brasileiros para seus filhos, falaria da coragem e do talento de Clementina de Jesus, e contaria para a pequena sobre todos os sofredores que ajudaram a construir tudo o que eles estavam vendo desde que nasceram, mostraria a história dos oprimidos que nunca se entregaram, mas desmantelaria para os futuros filhos os mitos falsos dos opressores, os mesmo falsos heróis que matavam índios e negros e depois ganhavam estátuas espalhadas pela cidade (FERRÉZ, 2014, P. 842).

O viver na contramão do bairro de Paulo era reconhecido e querido também pelos outros moradores, que falavam dele sempre como exemplo de boa conduta e de luta para conseguir entrar em uma faculdade. No entanto, Paulo também sonhava uma vida melhor para as crianças da sua comunidade e planejava um dia montar uma organização de acolhimento e educação, que fosse capaz de dar às crianças do bairro um desenvolvimento que não fosse uma "ruína". Nesse sentido, como vimos no trecho anterior, Nzinga Mbandi aparece como parte de uma herança cultural desconhecida pela maior parte da sua comunidade, mas que para Paulo significava, assim como Zumbi, Anastácia e Clementina, exemplos de resistência, de coragem, de luta e de talento do povo negro.

Certamente a tão sonhada instituição desmantelaria a história oficial dos opressores e restituiria a verdade sobre a história e as lideranças negras. No entanto, apesar do romance indicar os vários livros lidos por Paulo, nenhum deles se refere diretamente à Nzinga Mbandi, assim como também não há indicações de uma transmissão oral de sua história. Não há, portanto, no romance, um diálogo explícito com outros textos históricos, seja por fonte escrita ou oral. Apesar de desconhecida a origem das informações de Paulo sobre Nzinga, podemos dizer que no texto a Ngola do Ndongo e Matamba é construída a partir de uma perspectiva 


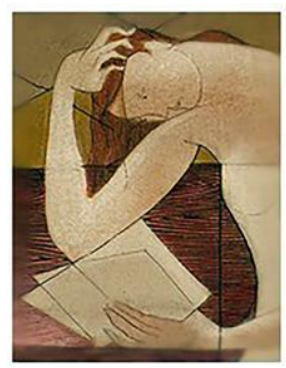

Nau Literária

crítica e teoria da literatura em língua portuguesa PPG-LET UFRGS

ISSN 1981-4526

https://seer.ufrgs.br/NauLiteraria

Vol.16, n. 2 -2020

Dossiê Literatura e Gênero

que nega a sua história oficial e colonial de barbárie e selvageria, ao mostrá-la como uma heroína importante para os negros e negras brasileiros.

A história de Paulo, no entanto, não é só feita desse ódio que o leva a questionar e sonhar mudanças para a sua comunidade, infelizmente, como dissemos anteriormente, ainda que viva na contramão do bairro, há um ódio que parece contaminar e destruir a todos que vivem nele. Nesse sentido, é o assassinato de Auxiliadora que não só faz de Paulo um assassino, uma vez que ele vinga a sua amada com a morte de Modelo, mas também o insere ativamente, ainda que de forma circunstancial, no ciclo de violência do bairro.

\section{Conclusões}

Dentre os cinco textos analisados neste artigo, apenas o de Basílio da Gama (1791) narra Nzinga Mbandi a partir de uma perspectiva colonial. Nesse sentido, o poema vai recuperar tópicos do imaginário colonial português, como a selvageria e barbárie, para descrever a rainha angolana. Nos outros textos, no entanto, Nzinga Mbandi é construída a partir de uma perspectiva anticolonial e/ou pós-colonial, que serve para reafirmar o orgulho de sua descendência, como em Luís Gama (1859), o seu papel na resistência negra no Brasil, como em Antonio Callado (1983), o seu lugar de resistência na memória afro-brasileira feminina, como em Conceição Evaristo (1996), e o seu lugar de heroína na história (afro)brasileira, como em Ferréz (2003).

Quanto ao diálogo com fontes históricas, ao contrário dos outros textos brasileiros, analisados em artigo anterior (MAIA, 2020), que dialogam explicitamente com textos históricos, os textos analisados aqui dialogam mais com o testemunho oral, como em Basílio da Gama (1791), com a oralidade, como em Conceição Evaristo (1996), e com fontes literárias, como em Luís Gama (1859). Enquanto os textos de Callado (1983) e Ferréz (2003) não indicam possíveis fontes históricas e/ou literárias.

É preciso dizer também que a localização de outros textos literários brasileiros que narram Nzinga Mbandi é tarefa não esgotada, e pode revelar novas perspectivas para o imaginário literário brasileiro sobre a Ngola do Ndongo e Matamba. No entanto, podemos 


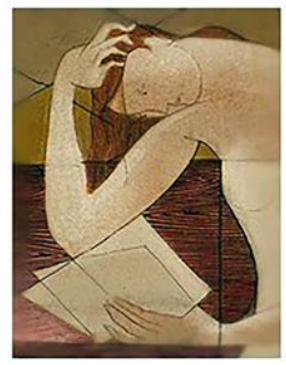

Nau Literária

crítica e teoria da literatura em língua portuguesa PPG-LET UFRGS

ISSN 1981-4526

https://seer.ufrgs.br/NauLiteraria

Vol.16, n. 2 -2020

Dossiê Literatura e Gênero

dizer que não só há um aumento significativo na produção de textos literários sobre Nzinga a partir dos anos noventa do último século, como também há uma tendência nesses textos em narrá-la a partir de perspectivas anticoloniais.

Nesse sentido, poderíamos apontar também para o poema Vozes x Armas, de Edu Omo Oguian, publicado em Cadernos Negros, número 7, em 1984, onde Nzinga aparece ao lado de outros chefes guerreiros de África e Brasil; o conto A roda bantu, de Henrique Antunes Júnior, publicado em 2004, no livro Tear africano: contos afrodescendentes, onde Nzinga aparece dividida em quatro mulheres do Ndongo, que se dirigem a uma reunião entre os sábios do mundo; e o poema América Negra, de Elio Ferreira, publicado em Cadernos Negros, número 27, em 2004, onde o sujeito lírico, assim como Luís Gama, se coloca orgulhosamente como um neto da Rainha Ginga.

\section{Referências}

AMÂNCIO, Iris. A ginga da Rainha. Belo Horizonte: Mazza Edições, 2005.

BENJAMIN, Roberto. A Rainha Ginga. João Pessoa: Editora Grafset, 2008.

BOSI, Alfredo. As sombras das luzes na condição colonial: sobre a poesia de Basílio da Gama. In: BETTO, Frei (Org). Utopia urgente. Sâo Paulo: EDUC, 2002.

BRAZ, Pedro; COQUEIRO, Wilma; SILVA, Sandro. Em Milenar resistência e Reexistência: história e luta no poema "A noite não adormece nos olhos das mulheres", de Conceição Evaristo. Contexto, n.37, 2020.

CADORNEGA, António. História Geral das Guerras Angolanas. Lisboa: Agência-Geral do Ultramar, 1972.

CALLADO, Antonio. A revolta da cachaça. Rio de Janeiro: Nova Fronteira, 2004.

CAMPOS, Fernando. Conflitos na dinastia Guterres através da sua cronologia. África: Revista do Centro de Estudos Africanos da USP, n.27-28, p. 23-43, 2007.

CARNEIRO, Vinícius Gonçalves. Reflexões quanto à literatura marginal brasileira: comparando Ferréz a sua tradição literária. Estudos de Literatura Brasileira Contemporânea, n. 50, p. 254-276, 2017. 


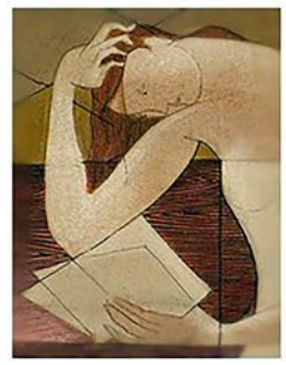

Nau Literária

crítica e teoria da literatura em língua portuguesa PPG-LET UFRGS

ISSN 1981-4526

https://seer.ufrgs.br/NauLiteraria

Vol.16, n. 2 -2020

Dossiê Literatura e Gênero

CASTRO, Felipe, et al. Quelé, a voz da cor: biografia de Clementina de Jesus. Rio de Janeiro: Civilização Brasileira, 2017.

CAVAZZI, Antonio. Descrição Histórica dos Três Reinos do Congo, Matamba e Angola. Lisboa: Junta de Investigações do Ultramar, 1965.

CHIAPPINI, Ligia. Roteiro de leitura e notas in: CALLADO, Antonoi. A revolta da cachaça. Rio de Janeiro: Nova Fronteira, 2004.

CORDEIRO DA MATTA, Joaquim Dias. A verdadeira rainha Ginga, in: Novo Almanach de Lembranças Luzo-brazileiro para o ano de 1883. Lisboa: Typographia Lisboa, p. 229-232, 1882.

EVARISTO, Conceição. A noite não adormece nos olhos das mulheres. In: Cadernos negros 19: poesia. São Paulo: Quilombhoje, 1996.

FERREIRA, Élio. América Negra. In: Cadernos negros 27: poemas afro-brasileiros. São Paulo: Quilomboje, 2004.

FERREIRA, Ligia Fonseca. Com a palavra Luiz Gama: poemas, artigos, cartas, máximas. São Paulo: Imprensa Oficial do Estado de São Paulo, 2011.

FERREIRA, Lígia Fonseca. Luiz Gama autor, leitor, editor: revisitando as Primeiras Trovas Burlescas de 1859 e 1861. Revista Estudos Avançados, n.33, 2019.

FERRÉZ. Manual Prático do Ódio. São Paulo: Planeta, 2014, versão kindle.

FRANCO, Aninha; DIAS, Marcos. A comida de Nzinga. Salvador: Theatro XVIII, 2007.

GAMA, Basílio da. Quitubia. In: Obras poéticas de José Basilio da Gama. Rio de Janeiro: Garnier, 1920.

GAMA, Luís. Lá vem verso. In: Primeiras Trovas Burlescas de Getulino. São Paulo: Typographia Dous de Dezembro de Antonio Louzada Antunes, 1859.

GLASGOW, Roy. Nzinga: resistência africana à investida do colonialismo português em Angola 1582-1663. São Paulo: Perspectiva, 2013.

JESUS, Clementina de. Cangoma me chamou: O canto dos escravos [1982]. Disponível em: <https://www.youtube.com/watch?v=zFk4A-xo_Vg>. Acesso em 24 abr. 2020. 


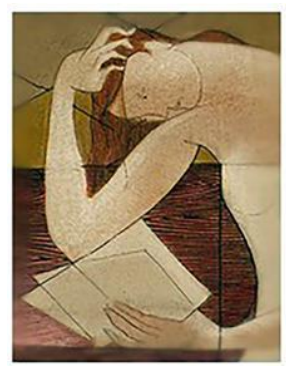

Nau Literária

crítica e teoria da literatura em língua portuguesa PPG-LET UFRGS

ISSN 1981-4526

https://seer.ufrgs.br/NauLiteraria

Vol.16, n. 2 -2020

Dossiê Literatura e Gênero

JÚNIOR, Henrique Cunha. A roda bantu. In: Tear africano: contos afrodescendentes. São Paulo: Selo Negro, 2004.

MAIA, Helder Thiago. Entra na roda e ginga: imaginário literário brasileiro sobre a Rainha Ginga. Crioula, n. 25, 2020.

MAIA, Helder Thiago; LUGARINHO, Mário. Entre as guerras angolanas e a invenção do mundo: gênero e sexualidade de Nzinga Mbandi na literatura angolana. No prelo (2020a).

MAIA, Helder Thiago; LUGARINHO, Mário. Uma rainha em três continentes: gênero e sexualidade em torno de Nzinga Mbandi. No prelo. (2020b).

MATTOS, Hebe Maria. Escravidão e cidadania no Brasil monárquico. São Paulo: Companhia das Letras, 1999.

MIRANDA, Fernanda. Silêncios prescritos: estudos de romances de autoras negras brasileiras. Rio de Janeiro: Malê, 2019.

MORATO, Fernando. A nojenta prole da rainha Ginga, em parte aos homens semelhante: Bocage e a representação de negros e afro-descendentes no Neoclassicismo português. Revista Letras, Curitiba, Ufpr, n.97, p. 90-105, 2018.

MUSSA, Alberto. O trono da Rainha Jinga. Rio de Janeiro: Record, 2017.

NAGAKOME, Patrícia; SOUSA, Regina. Protagonismo negro, autoria branca: a Revolta da Cachaça e Arena conta: Zumbi. Vagão-volume, p. 65-76, 2011.

NASCIMENTO, Abdias do. Teatro experimental do negro: trajetória e reflexões. Estudos avançados, vol. 18, n. 50, 2004.

OGUIAN, Edu Omo. Vozes x Armas. In: Cadernos Negros 7. São Paulo: Quilombhoje, 1984.

PANTOJA, Selma. Revisitando a rainha Nzinga: histórias e mitos das histórias. In: MATA, Inocência (Org). A Rainha Nzinga Mbandi: história, memória e mito. Lisboa: Edições Colibri, 2014.

SANTOS, Telma Gonçalves. Comércio de tecidos europeus e asiáticos na África CentroOcidental: fraudes e contrabando no terceiro quartel do século XIII. Dissertação (Mestrado em História). Universidade de Lisboa, 2014.

SAPIÊNCIA, Ricon. A coisa tá preta. Galanga Livre [2017]. Disponível em: <https://www.youtube.com/watch?v=REQo_7MaP9U>. Acesso em 28 abr. 2020. 


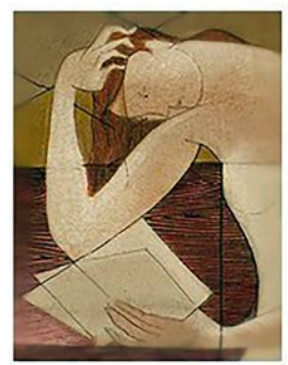

Nau Literária

crítica e teoria da literatura em língua portuguesa

PPG-LET UFRGS

ISSN 1981-4526

https://seer.ufrgs.br/NauLiteraria

Vol.16, n. 2 -2020

Dossiê Literatura e Gênero

SILVEIRA, Eliane Pereira. Manual Prático do Ódio: a ficção de um subalterno. Revista Idéias, n.22, p. 33-37, 2005.

VERISSIMO, José. Basilio da Gama: sua vida e suas obras. In: Obras poéticas de José Basilio da Gama. Rio de Janeiro: Garnier, 1920. 